\title{
Subjective sleep quality and association with depression syndrome, chronic diseases and health-related physical fitness in the middle-aged and elderly
}

Min-Fang Hsu ${ }^{1 \dagger}$, Kang-Yun Lee ${ }^{2,3+}$, Tsung-Ching Lin ${ }^{4,5,6}$, Wen-Te Liu' $2,3,7$ and Shu-Chuan $\mathrm{Ho}^{2,7,8^{*}}$ (D)

\begin{abstract}
Background: As a complex phenomenon, sleep quality is difficult to objectively define and measure, and multiple factors related to sleep quality, such as age, lifestyle, physical activity, and physical fitness, feature prominently in older adult populations. The aim of the present study was to evaluate subjective sleep quality using the Pittsburgh Sleep Quality Index (PSQI) and to associate sleep quality with health-related physical fitness factors, depressive symptoms, and the number of chronic diseases in the middle-aged and elderly.

Methods: We enrolled a total of 283 middle-aged and elderly participants from a rehabilitation clinic or health examination department. The PSQI was used to evaluate sleep quality. The health-related fitness assessment included anthropometric and physical fitness parameters. Depressive symptoms were measured with the Center for Epidemiologic Studies Depression Scale (CES-D) short form. Data were analyzed with SPSS 18.0, and descriptive statistics and logistic regression analysis were used for the analyses.

Results: Overall, 27.9\% of participants in this study demonstrated bad sleepers (with a PSQI score of > 5), 10.2\% of study participants frequently used sleep medication to help them fall asleep, and 6.0\% reported having significant depressive symptoms (with a CES-D score of $\geq 10$ ). There are two major findings: (1) depression symptoms, the number of chronic diseases, self-rated health, and arthritis were significantly associated with a poor sleep quality, and (2) the 2-min step test was associated with longer sleep latency. These results confirmed that the 2-min step was associated with a longer sleep latency among the health-related physical fitness items.
\end{abstract}

Conclusions: Our study found that depressive syndrome, chronic disease numbers, a poor self-rated health status, and arthritis were the main risk factors that influenced subjective sleep quality.

Keywords: Subjective sleep quality, Pittsburgh sleep quality index, Health-related physical fitness, Depression symptoms, Arthritis

\footnotetext{
* Correspondence: shu-chuan@tmu.edu.tw

${ }^{\dagger}$ Min-Fang Hsu and Kang-Yun Lee contributed equally to this work.

2Division of Pulmonary Medicine, Department of Internal Medicine, Shuang

Ho Hospital, Taipei Medical University, New Taipei City, Taiwan

${ }^{7}$ School of Respiratory Therapy, College of Medicine, Taipei Medical

University, Taipei City, Taiwan

Full list of author information is available at the end of the article
}

C The Author(s). 2021 Open Access This article is licensed under a Creative Commons Attribution 4.0 International License, which permits use, sharing, adaptation, distribution and reproduction in any medium or format, as long as you give appropriate credit to the original author(s) and the source, provide a link to the Creative Commons licence, and indicate if changes were made. The images or other third party material in this article are included in the article's Creative Commons licence, unless indicated otherwise in a credit line to the material. If material is not included in the article's Creative Commons licence and your intended use is not permitted by statutory regulation or exceeds the permitted use, you will need to obtain permission directly from the copyright holder. To view a copy of this licence, visit http://creativecommons.org/licenses/by/4.0/. The Creative Commons Public Domain Dedication waiver (http://creativecommons.org/publicdomain/zero/1.0/) applies to the data made available in this article, unless otherwise stated in a credit line to the data. 


\section{Background}

As a complex phenomenon, sleep quality is difficult to define and measure objectively [1], and it is not directly associated with sleep quantity. The best assessment of sleep quality includes both subjective and objective measures [2]. Polysomnography (PSG) is the gold standard objective measure of sleep [3], and the Pittsburgh Sleep Quality Index (PSQI) is a widely used self-administered sleep questionnaire [1]. Self-reported sleep does not correlate well with PSG-defined sleep [4]. Multiple factors are related to sleep quality in old age, including lifestyle, physical activity, and physical fitness; moreover, alcohol consumption patterns [5], depressive symptoms [6], and rheumatoid arthritis (RA) [7] may also affect sleep quality. Among multiple factors related to sleep quality, recent studies began to focus on physical activity and physical fitness $[8,9]$.

Sleep is important to physical, cognitive, and psychological health. Sleep quality changes as a function of normal aging, there is no association between subjective sleep quality and cognitive performance in healthy young adults [10], and only half of middle-aged and elderly Chinese reported good sleep quality [11]. Agerelated sleep changes may lead to poor sleep quality in older adults with physical or psychiatric disorders [12]. Many middle-aged and older adults do not sleep well, and they are more likely to take pharmacological sleep aids [13]. Studies revealed that $49 \%$ of communitydwelling older adults reported poor sleep quality [6], and $41.9 \%$ of adults aged 60 years or older suffer from sleep disturbances in Taiwan [14]. Sleep disturbances are also associated with lower physical fitness levels, a reduced health-related quality of life [15], nocturia, poor selfreported functional status, and one's mental status [14]. Moreover, symptoms of depression were identified as factors most significantly associated with poor sleep quality among older adults $[6,14]$.

Young female adults with poor sleep quality are more likely to have lower levels of physical activity (muscle endurance, flexibility, and cardiovascular fitness) [16]. Studies revealed the benefits of physical activity and regular exercise in improving sleep quality and reducing the occurrence of sleep disturbances $[8,9,17]$ in middle-aged and elderly adults. Physical activity in middle-aged and elderly adults differs from that of younger populations. Health-related fitness is the ability to become and remain physically healthy. Health-related physical fitness includes muscle strength, muscle endurance, cardiovascular endurance, joint flexibility, and body composition (American Alliance for Health, Physical Education, Recreation and Dance, 1980). Few studies have investigated relationships of depression with the quality of sleep and health-related physical fitness level. Therefore, the aim of the present study was to evaluate the subjective sleep quality using the PSQI, depression, and chronic diseases and their associations with the influence of health-related physical fitness factors in community-dwelling middle-aged and elderly.

\section{Methods \\ Design and sample}

A cross-sectional survey was conducted in our study. We recruited older adults in northern Taiwan from August 2010 to July 2013. The inclusion criteria of the sample were as follows: (a) aged 40 years or older; (b) with no ambulatory problems or using any assistance for walking; and (c) able to communicate verbally. Those who had severe cardiovascular disease, neurological disease, or musculoskeletal impairment were excluded. In total, the sample size was 283 individuals. The study was approved (no. 098101-3) by the Ethics Committee of Far Eastern Memorial Hospital, and all subjects provided written informed consent before they were allowed to participate in the study.

\section{Measures}

The evaluated characteristics of respondents included sex, age, marital status, educational level, religious beliefs, number of current diseases (hypertension, heart disease, diabetes mellitus, pulmonary disease, peptic ulcers, liver disease, arthritis, osteoporosis, and cancer), smoking and alcohol consumption habits, tea and coffee consumption, and regular exercise (more than $30 \mathrm{~min}$ at least 3 days per week) [6]. Self-ratings of the health status, which reflected an individual's personal perception of their overall health condition, were indicated on a 5point Likert scale (scored $1=$ very poor to $5=$ excellent).

The PSQI was used to evaluate sleep quality [1], and the Chinese version (CPSQI) was used in this study [18]. The CPSQI had an overall reliability coefficient of 0.82 $\sim 0.83$ for community-dwelling adults with primary insomnia and control subjects, and also acceptable testretest reliability over a $14 \sim 21$-day interval with a coefficient of 0.85 for all subjects and 0.77 for primary insomniacs [18]. Participants self-rate their sleep situation with respect to seven components: sleep duration, sleep disturbance, sleep latency, daytime dysfunction, sleep efficiency, subjective sleep quality, and use of sleep medication in the past month. The score of each component ranges $0 \sim 3$, and the sum of these component scores, ranging $0 \sim 21$, is the total score that serves as a measure of sleep quality. A global score higher than five was defined as an indicator of bad sleeper [1]. In our study, we also used the original scores of the seven components and individually recoded them as dichotomous variables to examine the association of the correlates with these seven components. 
The health-related fitness assessment included the following anthropometric and physical fitness measurements: (1) body weight and height were measured with a calibrated scale (within $\pm 0.1 \mathrm{~cm}$ ), and participants were asked to wear light clothes and no shoes. Body-mass index (BMI) calculated according to the body weight (kg) divided by the height (in $\mathrm{m}^{2}$ ); (2) mid-arm circumference, waist circumference, and buttock circumference measured according to standard methods; (3) body composition assessed using a bioelectrical impedance analysis (TANITA's body composition analyzer, TBF 300, Tokyo, Japan) to derive the percentage of body fat, fat mass, and fat-free mass; and (4) physical activity measured using the International Physical Activity Questionnaire (IPAQ) short version, which comprises four generic items. The questionnaire was developed in Geneva in 1998 and has undergone extensive reliability and validity testing across many countries and has been translated into several different languages. We adopted the Taiwanese version [19]. Participants were asked to report their physical activity during the previous 7 days as an estimate of their habitual level of physical activity. IPAQ scores were categorized into three levels of physical activity: low, moderate, and high.

Physical fitness assessment: We used a set of senior fitness test tools developed by Accuratus International Health Company of Taiwan [20]. The test contained the following seven items: (1) sit-and-reach test, which is commonly used to measure the flexibility of the lower back; (2) one-leg stance test, which is used to assess static balance; (3) 2-min step test, which assesses cardiovascular endurance; (4) back muscle strength, which measures the maximal isometric strength of the trunk muscles in a standing posture with $30^{\circ}$ lumbar flexion using a back muscle strength meter; (5) 30-s chair-stand test, which is used to assess lower-body strength; (6) grip strength, which measures the muscle strength of the upper arms; and (7) up-and-go test, which measures the speed, agility, and balance when the body is moving. For grip strength (no. 6), participants were asked to stand and grasp a grip strength-measuring device (Jamar ${ }^{\bullet}$ Plus+ Digital Hand Dynamometer; Sammons Preston, Rolyon, Bolingbrook, IL, USA). They performed this action three times, and the best score was recorded. All physical fitness measurements were performed by welltrained personnel, and the results were recorded on a computer.

Depressive symptoms were measured using the Center for Epidemiologic Studies Depression Scale (CES-D) short form [21]. The Chinese version of 10 self-reported items was used to measure depressive symptoms that occurred in the previous week. The score of each question ranges $0 \sim 3$, with the total score ranging $0 \sim 30$; we considered that a score of $\geq 10$ indicated depression [21].

\section{Statistical analysis}

Descriptive statistics were recorded for each variable of the characteristics of subjects and health-related fitness, with quantitative data shown as the mean and standard deviation (SD). Differences in comparisons of two group were analyzed with an independent $t$-test, Chi-squared test, Fisher's exact test, and Mann-Whitney U-test. Spearman's correlation was used for the PSQI and health-related fitness. A logistic regression analysis was performed to assess the characteristics and physical fitness associated with PQSI variables. The level of significance was set to $\alpha=0.05$. Data were analyzed with SPSS for Windows vers. Ninteen software (IBM, SPSS, Chicago, IL, USA).

\section{Results}

In total, 283 individuals completed the entire physical fitness evaluation, and the PSQI questionnaire. Table 1 lists participants' characteristics. The mean age was $59 \pm$ 7.3 years, and approximately third-fourths of the study population were female and had religious beliefs. Only $5.3 \%$ of participants had a smoking history, $18 \%$ used alcohol at least once a week, about $60 \%$ used tea and coffee at least once a week, $49.5 \%$ engaged in regular exercise, only $5.7 \%$ did not achieve a moderate to high level of physical activity, 57.2\% (162 subjects) had chronic disease, and $6 \%$ had depressive symptoms. Older adults, those with less alcohol use, and those with fewer depression symptom had significantly better sleep. A greater number of chronic diseases, especially heart disease and arthritis, were associated with poor sleep quality.

Overall, Table 2 shows the distribution of the quality of sleep according to the PSQI questionnaire. Global scores indicated that $27.9 \%$ of participants had poor sleep quality. The majority of participants (69.6\%) reported that they usually had more than $7 \mathrm{~h}$ of sleep at night, most (86.9\%) reported only a slight problem with sleep disturbances, and $26.9 \%$ of participants reported needing more than $30 \mathrm{~min}$ to fall asleep. Results of sleep efficiency revealed that three-quarters of participants had sleep efficiency exceeding $87.6 \%$; however, approximately one-third of participants self-rated their sleep quality as poor, and most (83.7\%) had not used sleep medication during the previous month.

Results of the distribution of health-related fitness between good and bad sleepers using the Mann-Whitney U-test are presented in Table 3. Participants with bad sleepers reported significantly higher depression symptoms, chronic disease numbers, and up-and-go times than participants with a good quality of sleep. In terms of self-rated health, participants with a poor quality of sleep reported lower health conditions. Other anthropometric indices and physical fitness parameters did not 
Table 1 Characteristics of the study subjects $(N=283)$

\begin{tabular}{|c|c|c|c|c|}
\hline \multirow[b]{2}{*}{ Variable } & \multirow[b]{2}{*}{$n(\%)$} & \multicolumn{2}{|c|}{ Quality of sleep } & \multirow[t]{2}{*}{$p$ value } \\
\hline & & Good $n(\%)$ & Poor $n(\%)$ & \\
\hline Age (years) $(59 \pm 7.3)$ & & & & $0.020^{\#}$ \\
\hline$<65$ & $227(80.2)$ & $161(70.9)$ & $66(29.1)$ & \\
\hline $65 \sim 74$ & $45(15.9)$ & $38(54.4)$ & $7(15.6)$ & \\
\hline$\geq 75$ & $11(3.9)$ & $5(45.5)$ & $6(54.5)$ & \\
\hline Sex & & & & 0.317 \\
\hline Male & $60(21.2)$ & $47(78.3)$ & $13(21.7)$ & \\
\hline Female & $223(78.8)$ & $157(71.2)$ & $66(22.6)$ & \\
\hline Religious beliefs & & & & 0.513 \\
\hline No & $61(21.6)$ & $46(75.4)$ & 15 (24.6) & \\
\hline sYes & $222(78.4)$ & $158(71.2)$ & $64(28.8)$ & \\
\hline Smoking history & & & & 0.284 \\
\hline No & $268(94.7)$ & $195(72.8)$ & $73(27.2)$ & \\
\hline Yes & $15(5.3)$ & $9(60.0)$ & $6(40.0)$ & \\
\hline Alcohol consumption & & & & 0.048 \\
\hline No & $232(82.0)$ & $162(69.8)$ & $70(30.2)$ & \\
\hline At least once a week & $51(18.0)$ & $42(82.4)$ & $9(17.6)$ & \\
\hline Tea consumption & & & & 0.407 \\
\hline No & $116(41.0)$ & $85(73.3)$ & $31(26.7)$ & \\
\hline At least once a week & $167(59.0)$ & $119(72.3)$ & $48(28.7)$ & \\
\hline Coffee consumption & & & & 0.521 \\
\hline No & $110(38.9)$ & $79(71.8)$ & $31(28.2)$ & \\
\hline At least once a week & $173(61.1)$ & $125(72.3)$ & $48(27.7)$ & \\
\hline Regular exercise & & & & 0.526 \\
\hline No & $143(50.5)$ & $101(70.6)$ & $42(29.4)$ & \\
\hline Yes & $140(49.5)$ & $103(73.6)$ & $37(26.4)$ & \\
\hline Chronic disease $^{a}$ & & & & 0.025 \\
\hline No & $121(42.8)$ & $95(78.5)$ & $26(21.5)$ & \\
\hline Yes & $162(57.2)$ & $109(67.3)$ & $53(32.7)$ & \\
\hline Heart disease & & & & 0.017 \\
\hline No & $250(88.3)$ & $186(74.4)$ & $64(25.6)$ & \\
\hline Yes & $33(11.7)$ & $18(54.5)$ & $15(45.5)$ & \\
\hline Arthritis & & & & 0.002 \\
\hline No & $258(91.2)$ & $193(74.8)$ & $65(25.2)$ & \\
\hline Yes & $25(8.8)$ & $11(44.0)$ & $14(56.0)$ & \\
\hline Physical activity ${ }^{\mathrm{b}}$ (Mets) & & & & $0.949^{\#}$ \\
\hline Low & $15(5.7)$ & $11(73.3)$ & $4(26.7)$ & \\
\hline Moderate & $135(51.1)$ & $95(70.4)$ & $40(29.6)$ & \\
\hline High & $114(43.2)$ & $83(72.8)$ & $31(27.2)$ & \\
\hline Depressive symptoms $^{c}$ & & & & 0.004 \\
\hline No & $264(94.0)$ & $195(73.9)$ & $69(26.1)$ & \\
\hline Yes & $17(6.0)$ & $7(41.2)$ & $10(58.8)$ & \\
\hline
\end{tabular}

${ }^{a}$ Chronic diseases included heart disease, arthritis, hypertension, diabetes mellitus, lung disease, peptic ulcers, liver disease, osteoporosis, gout, and cataracts. Heart disease and arthritis were significant, while the others were not. ${ }^{b}$ mean \pm standard deviation: $4129.72 \pm 4811.94 ;{ }^{c}$ CES-D score:2.74 $\pm 4.02 .{ }^{*}$ Fisher's exact test. Mets, metabolic equivalents 
Table 2 Distribution of quality of sleep

\begin{tabular}{|c|c|c|}
\hline Variable items & Number & Percent \\
\hline \multicolumn{3}{|l|}{ Sleep duration (h) } \\
\hline $0: \geq 7$ & 197 & 69.6 \\
\hline $1: 6 \sim 6.9$ & 66 & 23.3 \\
\hline $2: 5 \sim 5.9$ & 15 & 5.3 \\
\hline $3: \leq 4.9$ & 5 & 1.8 \\
\hline \multicolumn{3}{|l|}{ Sleep disturbance (scores) } \\
\hline $0: 0$ & 19 & 6.7 \\
\hline 1: $1 \sim 9$ & 246 & 86.9 \\
\hline 2: $10 \sim 18$ & 17 & 6.0 \\
\hline 3: $19 \sim 27$ & 1 & 0.4 \\
\hline \multicolumn{3}{|l|}{ Sleep latency (min) } \\
\hline $0: \leq 15$ & 142 & 50.2 \\
\hline 1: $16 \sim 30$ & 65 & 23.0 \\
\hline $2: 31 \sim 60$ & 46 & 16.3 \\
\hline $3: \geq 60$ & 30 & 10.6 \\
\hline \multicolumn{3}{|l|}{ Daytime dysfunction } \\
\hline 0: Very good & 213 & 75.3 \\
\hline 1: Fairly good & 49 & 17.3 \\
\hline 2: Fairly bad & 19 & 6.7 \\
\hline 3: Very bad & 2 & 0.7 \\
\hline \multicolumn{3}{|l|}{ Sleep efficiency (\%) } \\
\hline $0: \geq 85$ & 248 & 87.6 \\
\hline 1: $75 \sim 84$ & 23 & 8.1 \\
\hline $2: 65 \sim 74$ & 7 & 2.5 \\
\hline $3: \leq 64$ & 5 & 1.8 \\
\hline \multicolumn{3}{|l|}{ Subjective sleep quality } \\
\hline 0 : Very good & 32 & 11.3 \\
\hline 1: Fairly good & 162 & 57.2 \\
\hline 2: Fairly bad & 63 & 22.3 \\
\hline 3: Very bad & 26 & 9.2 \\
\hline \multicolumn{3}{|l|}{ Use of sleep medication } \\
\hline 0 : Not during past month & 237 & 83.7 \\
\hline 1: Less than once a week & 10 & 3.5 \\
\hline 2: Once or twice a week & 7 & 2.5 \\
\hline 3: Three or more times a week & 29 & 10.2 \\
\hline \multicolumn{3}{|l|}{ Global sleep quality } \\
\hline Good quality $(\leq 5)$ & 204 & 72.1 \\
\hline Poor quality (> 5) & 79 & 27.9 \\
\hline
\end{tabular}

significantly differ between participants with good and those with poor quality of sleep.

Table 4 shows results of Spearman's correlations between the PSQI and health-related fitness. In a basic condition, depression symptoms $(r=0.491, p=0.000)$, and chronic disease numbers $(r=0.200, p=0.001)$ were significantly positively correlated with the PSQI, and self-rated health $(r=-0.391, p=0.000)$ was significantly negatively correlated with the PSQI. As to health-related fitness, sit-and-reach $(r=-0.131, p=0.028), 2$-min steps $(r=-0.133, p=0.026)$, and up-and-go $(r=-0.169, p=$ $0.004)$ were significantly negatively correlated with the PSQI. Other health-related fitness factors were not significantly correlated with the PSQI (all $p>0.05$ ).

Results of the logistic regression analysis are presented in Tables 5 and 6 with each of the seven components of the PSQI and the global score as dependent variables. Covariates of age, sex, alcohol use, depression, number of chronic diseases, self-rated health, arthritis, and the four physical fitness items were used as independent variables. Results were as follows. Only depression was associated with a short sleep duration $(\mathrm{OR}=1.172, p<$ $0.05)$; depression $(\mathrm{OR}=1.225, p<0.001)$ and arthritis $(\mathrm{OR}=5.515, p<0.05)$ were associated with sleep disturbances. Depression symptoms $(\mathrm{OR}=1.096, p<0.05)$, chronic disease numbers $(\mathrm{OR}=0.604, p<0.0)$, self-rated health $(\mathrm{OR}=0.885, p<0.01)$, and 2 -min steps $(\mathrm{OR}=$ $0.985, p<0.05)$ were associated with a longer sleep latency, and only depression $(\mathrm{OR}=1.143, p<0.01)$ was associated with daytime dysfunction. No other physical fitness items were associated with poor sleep efficiency; depression ( $\mathrm{OR}=1.260, p<0.001)$ and self-rated health $(\mathrm{OR}=0.856$ and $p<0.001)$ were associated with poor subjective sleep quality; depression $(\mathrm{OR}=1.148, p<0.01)$ and self-rated health $(\mathrm{OR}=0.869, p<0.01)$ were associated with use of sleep medication; and depressive symptoms $(\mathrm{OR}=1.220, p<0.001)$, chronic disease numbers $(\mathrm{OR}=0.524, p<0.05)$, self-rated health $(\mathrm{OR}=0.865, p<$ $0.001)$, and arthritis $(\mathrm{OR}=4.562, p<0.01)$ were associated with poor sleep quality. Among the controlling variables, sex, alcohol use, heart disease, chair stand in $30 \mathrm{~s}$, up-and-go, and constant were not associated with any component of the PQSI.

\section{Discussion}

Our study have two major findings: (1) depression symptoms, the number of chronic diseases, self-rated health, and arthritis were significantly associated with bad sleepers; and (2) the 2-min step test was associated with longer sleep latency.

These results confirmed the correlation of healthrelated physical fitness with sleep quality in the middleaged and elderly, and among the health-related physical fitness items measured, only the 2-min step test was associated with longer sleep latency. Our study revealed that $27.9 \%$ of participants reported bad sleepers. We discovered that $10.2 \%$ of study participants frequently used sleep medication to help them fall asleep, and 6.0\% reported having significant depressive symptoms (CES$\mathrm{D} \geq 10$ ). The components of sleep quality evaluated in 
Table 3 Distribution of health-related fitness between good and bad sleepers Using Mann-Whitney $U$ test $(N=283)$

\begin{tabular}{|c|c|c|c|}
\hline Variables & $\begin{array}{l}\text { Good Sleepers }(n=207) \\
\text { median (IQR) }\end{array}$ & $\begin{array}{l}\text { Bad Sleepers }(n=79) \\
\text { median (IRQ) }\end{array}$ & $z / p$ \\
\hline Age & $58.00(54.00-63.00)$ & $57.00(53.00-63.00)$ & $-0.585 / 0.558$ \\
\hline Depression & $0(0-2)$ & $4(2-7)$ & $-7.190 / 0.000$ \\
\hline Chronic disease numbers & $1(0-1)$ & $1(0-2)$ & $-2.125 / 0.034$ \\
\hline Self-rate health & $3(3-4)$ & $3(2-3)$ & $-5.399 / 0.000$ \\
\hline \multicolumn{4}{|l|}{ Anthropometric index } \\
\hline BMI (kg/m2) & $23.50(21.50-25.80)$ & $22.90(20.85-25.45)$ & $-1.278 / 0.201$ \\
\hline FFMl & $16.30(15.40-17.41)$ & $16.42(15.50-17.33)$ & $-0.050 / 0.960$ \\
\hline Mid-arm circumference $(\mathrm{cm})$ & $28.90(27.23-31.00)$ & $28.60(26.80-30.50)$ & $-1.239 / 0.215$ \\
\hline Waist / hip ratio & $0.85(0.80-0.90)$ & $0.84(0.79-0.89)$ & $-0.206 / 0.837$ \\
\hline \multicolumn{4}{|l|}{ Physical Fitness } \\
\hline Sit-and-reach $(\mathrm{cm})$ & $10.10(1.60-16.50)$ & $7.10(0.00-13.83)$ & $-1.351 / 0.177$ \\
\hline One leg stance (sec) & $60.00(55.00-60.00)$ & $60.00(49.75-60.00)$ & $-1.860 / 0.853$ \\
\hline Two-min step (times) & $113.00(99.00-124.00)$ & 107.5 (89.0-118.75) & $-1.782 / 0.075$ \\
\hline Chair stand in 30s (times) & $16.00(13.00-20.00)$ & $15.00(12.00-19.00)$ & $-1.593 / 0.111$ \\
\hline Grip muscle strength (kg) & $24.10(20.20-30.10)$ & $23.30(17.70-28.40)$ & $-1.682 / 0.093$ \\
\hline Up and go (sec) & $6.00(5.00-6.00)$ & $7.00(6.00-7.00)$ & $-2.324 / 0.020$ \\
\hline Back muscle strength (kg) & $48.00(31.50-64.50)$ & $44.25(30.38-59.00)$ & $1.388 / 0.165$ \\
\hline
\end{tabular}

$B M I$ Body mass index, FFMI Free Fat Mass Index, IRQ Interquartile range

Table 4 Spearman correlation between the Pittsburgh Sleep Quality Index (PSQI) and health-related fitness

\begin{tabular}{lll}
\hline & PSQI & \\
\cline { 2 - 3 } & $\boldsymbol{r}$ & $\boldsymbol{p}$ \\
\hline Basic condition & .004 & \\
Age & $\mathbf{4 9 1}$ & 0.952 \\
Depression & -.391 & $\mathbf{0 . 0 0 0}$ \\
Self-rate health & $\mathbf{0 . 2 0 0}$ & $\mathbf{0 . 0 0 0}$ \\
Chronic disease (Numbers) & & $\mathbf{0 . 0 0 1}$ \\
Anthropometric index & -.076 & \\
BMI & .001 & 0.204 \\
FFMl & .011 & 0.987 \\
Waist / hip ratio & & 0.857 \\
Physical Fitness & -.131 & \\
Sit-and reach & -.080 & $\mathbf{0 . 0 2 8}$ \\
One-leg stand & -.133 & 0.179 \\
Two-min steps & -.158 & $\mathbf{0 . 0 2 6}$ \\
Chair stand in 30s & -.105 & 0.080 \\
Grip muscle strength & -.169 & 0.195 \\
Up-and-go & -.100 & $\mathbf{0 . 0 0 4}$ \\
Back muscle strength & & 0.096 \\
\hline
\end{tabular}

this study were diverse, and sit-and reach, 2-min step test, and up-and-go physical fitness items were significantly correlated with components of sleep quality; but only the 2-min step test was associated with longer sleep latency after controlling for sex, age, current number of chronic diseases, self-rated health status, and depressive symptoms confounding factors. However, depressive symptoms, the number of chronic diseases, self-rated health status, and arthritis were main risk factors influencing bad sleepers among the middle-aged and elderly.

We found that depressive symptom caused a short sleep duration. Gerber et al. [22] reported that low fitness levels and a perceived lack of physical activity were associated with longer sleep onset latency. We similarly found better 2-min step endurance was associated with a lower risk of longer sleep latency. In our questionnaire, daytime functions, including driving, eating meals, and engaging in social activities, were less affected by depression. Lee and Lin [16] reported greater sit-and-reach distances in young women with favorable sleep quality, and we found that fewer depressive symptoms and chronic disease numbers, and better self-rated health were associated with subjective good sleepers. Furthermore, the self-rated health status also had major influences on sleep latency, subjective sleep quality, and global sleep quality.

In this study, the logistic regression analysis disclosed associations of sleep disturbances and poor sleep quality with arthritis. Patients with RA suffer from a variety of 
Table 5 Logistic regression analysis of poor sleep quality with the global score and with seven components of the Pittsburgh Sleep Quality Index (PSQI) $(N=283)$

\begin{tabular}{|c|c|c|c|c|c|c|c|c|}
\hline \multirow[t]{2}{*}{ Variable } & \multicolumn{8}{|l|}{ Odds ratio } \\
\hline & $\begin{array}{l}\text { Poor sleep } \\
\text { quality }\end{array}$ & $\begin{array}{l}\text { Short sleep } \\
\text { duration }\end{array}$ & $\begin{array}{l}\text { Sleep } \\
\text { disturbance }\end{array}$ & $\begin{array}{l}\text { Longer sleep } \\
\text { latency }\end{array}$ & $\begin{array}{l}\text { Daytime } \\
\text { dysfunction }\end{array}$ & $\begin{array}{l}\text { Poor sleep } \\
\text { efficiency }\end{array}$ & $\begin{array}{l}\text { Poor subjective } \\
\text { sleep quality }\end{array}$ & $\begin{array}{l}\text { Use of sleep } \\
\text { medication }\end{array}$ \\
\hline Age & 1.005 & 1.010 & 0.925 & 0.974 & 1.010 & 1.008 & 0.986 & 1.036 \\
\hline Sex & 1.529 & 4.753 & 3.910 & 0.836 & 1.027 & 2.465 & 1.238 & 0.737 \\
\hline Alcohol consumption & 0.573 & 0.876 & 1.015 & 0.790 & 0.826 & 1.747 & 0.648 & 0.405 \\
\hline CES-D score & $1.220^{* * *}$ & $1.172^{*}$ & $1.225^{* * *}$ & $1.096^{*}$ & $1.143^{*}$ & 1.003 & $1.260^{* * *}$ & $1.148^{* *}$ \\
\hline Chronic disease numbers & $0.524^{*}$ & 0.404 & 0.8722 & $0.604^{*}$ & 0.629 & 0.830 & $0.650^{*}$ & 0.962 \\
\hline Self-rated health & $0.865^{* * *}$ & 0.948 & 0.972 & $0.885^{* *}$ & 0.960 & 0.926 & $0.856^{* * *}$ & $0.869^{* *}$ \\
\hline Arthritis & $4.562^{* *}$ & 4.180 & $5.815^{* *}$ & 2.38 & 2.126 & 2.922 & 2.959 & 1.622 \\
\hline Heart disease & 2.296 & NA & 0.869 & 1.430 & 1.665 & NA & 1.046 & 2.298 \\
\hline Sit-and-reach & 0.991 & 0.956 & 0.962 & 0.994 & 0.980 & 0.985 & 1.004 & 0.994 \\
\hline Two-min step & 1.000 & 0.984 & 0.981 & $0.985^{*}$ & 1.003 & 0.998 & 0.993 & 0.993 \\
\hline Up-and-go & 1.109 & 1.130 & 1.384 & 1.044 & 1.109 & 1.063 & 1.098 & 0.994 \\
\hline
\end{tabular}

${ }^{*} p<0.05,{ }^{* *} p<0.01,{ }^{* * *} p<0.001$

CES-D Center for Epidemiological Studies Depression Scale, NA there are no variability in the data for short sleep duration and poor sleep efficiency column

symptoms such as joint pain, fatigue, stiffness, sleep disturbances, and functional disability [7]. High prevalence of abnormal sleep quality were observed in both RA and osteoarthritis patient populations. The most common abnormality was sleep fragmentation, with an increased sleep disturbance score [23]. Only $18.5 \%$ of RA patients reported good sleepers, with depression and risk of sleep apnea being independently associated with sleep impairment [24].

Older adults with a long sleep duration had weaker hand grip strength irrespective of muscle mass [25]. More muscle power corresponded to a lower probability of using sleep medication. Upper-arm muscle strength was a factor related to sleep medication use [24]. We found that sleep medication use was associated with self-rated health and depressive symptoms. Approximately $90 \%$ of patients with depression reported poor sleep quality [26], for which depressive symptoms may have a greater influence than physical fitness.

This study has several limitations, including a small sample size, an unbalanced number of men and women recruited, sleep measurement based on subjective descriptions, and the lack of a control group. Furthermore, many factors, such as those pertaining to genetics and the environment, were not considered in our study and may have influential effects on sleep quality [27].

Table 6 Logistic regression analysis of poor sleep quality with the global score and with seven components of Pittsburgh Sleep Quality Index (PQSI) $(N=283)$

\begin{tabular}{|c|c|c|c|c|c|c|c|c|}
\hline \multirow[t]{2}{*}{ Variable } & \multicolumn{8}{|c|}{$95 \%$ Confidence interval } \\
\hline & $\begin{array}{l}\text { Poor sleep } \\
\text { quality }\end{array}$ & $\begin{array}{l}\text { Short sleep } \\
\text { duration }\end{array}$ & $\begin{array}{l}\text { Sleep } \\
\text { disturbance }\end{array}$ & $\begin{array}{l}\text { Longer sleep } \\
\text { latency }\end{array}$ & $\begin{array}{l}\text { Daytime } \\
\text { dysfunction }\end{array}$ & $\begin{array}{l}\text { Poor sleep } \\
\text { efficiency }\end{array}$ & $\begin{array}{l}\text { Poor subjective } \\
\text { sleep quality }\end{array}$ & $\begin{array}{l}\text { Use of sleep } \\
\text { medication }\end{array}$ \\
\hline Age & $(0.960,1.052)$ & $(0.936,1.090)$ & $(0.846,1.011)$ & $(0.931,1.018)$ & $(0.941,1.083)$ & $(0.937,1.084)$ & $(0.943,1.032)$ & $(0.979,1.095)$ \\
\hline Sex & $(0.625,3.742)$ & $\begin{array}{l}(0.494 \\
45.703)\end{array}$ & $\begin{array}{l}(0.512 \\
29.751)\end{array}$ & $(0.383,1.825)$ & $(0.283,3.725)$ & $\begin{array}{l}(0.487 \\
12.475)\end{array}$ & $(0.528,2.902)$ & $(0.283,1.923)$ \\
\hline Alcohol consumption & $(0.234,1.404)$ & $(0.173,4.427)$ & $(0.193,5.338)$ & $(0.356,1.751)$ & $(0.212,3.222)$ & $(0.503,6.072)$ & $(0.281,1.497)$ & $(0.114,1.435)$ \\
\hline CES-D score & $(1.116,1.333)$ & $(1.043,1.318)$ & $(1.091,1.376)$ & $(1.015,1.183)$ & $(1.034,1.262)$ & $(0.884,1.137)$ & $(1.145,1.387)$ & $(1.051,1.235)$ \\
\hline Chronic disease numbers & $(0.789,6.684)$ & $(0.165,0.986)$ & $(0.389,1.951)$ & $(0.382,0.954)$ & $(0.306,1.294)$ & $(0.401,1.719)$ & $(0.403,1.049)$ & $(0.568,1.630)$ \\
\hline Self-rated health & $(0.792,0.944)$ & $(0.822,1.093)$ & $(0.833,1.135)$ & $(0.815,0.961)$ & $(0.838,1.100)$ & $(0.808,1.063)$ & $(0.785,0.934)$ & $(0.784,0.963)$ \\
\hline Arthritis & $\begin{array}{l}(1.513 \\
13.753)\end{array}$ & $\begin{array}{l}(0.503 \\
34.773)\end{array}$ & $\begin{array}{l}(1.115 \\
30.324)\end{array}$ & $(0.701,5.926)$ & $\begin{array}{l}(0.410 \\
11.408)\end{array}$ & $\begin{array}{l}(0.556 \\
15.351)\end{array}$ & $(0.995,8.798)$ & $(0.994,5.329)$ \\
\hline Heart disease & $(0.315,0.873)$ & NA & $(0.148,5.087)$ & $(0.511,3.999)$ & $(0.339,8.183)$ & NA & $(0.358,3.053)$ & $(0.776,6.808)$ \\
\hline Sit-and-reach & $(0.963,1.020)$ & $(0.914,0.999)$ & $(0.916,1.011)$ & $(0.967,1.023)$ & $(0.938,1.024)$ & $0.941,1.031)$ & $(0.975,1.033)$ & $(0.961,1.028)$ \\
\hline Two-min step & $(0.986,1.015)$ & $(0.960,1.009)$ & $(0.954,1.010)$ & $(0.972,0.999)$ & $(0.980,1.028)$ & $(0.975,1.021)$ & $(0.979,1.007)$ & $(0.975,1.011)$ \\
\hline Up-and-go & $(0.890,1.415)$ & $(0.767,1.666)$ & $(0.902,2.123)$ & $(0.826,1.319)$ & $(0.761,1.616)$ & $(0.726,1.554)$ & $(0.865,1.393)$ & $(0.752,1.315)$ \\
\hline
\end{tabular}




\section{Conclusions}

Beyond sleep duration, the quality of this time is important to consider. Middle-aged and older adults are more likely a result of declining sleep quality and duration associated with aging. Although Sleep quality is typically harder to measure because it can be subjective, with regard to cognition and health. Measurement of healthrelated physical fitness, that is, fitness related to disease prevention and health promotion. This study revealed that depressive symptoms, the number of chronic diseases, self-rated health status, and arthritis were the main risk factors that influenced global sleep quality among the middle-aged and elderly who participated in this study; and the 2-min step test for physical fitness was associated with longer sleep latency. The 2-min step test requires no expensive equipment and only a few square meters of space, has been used internationally with both healthy and diseased individuals, further research is required regarding the validity, reliability, and responsiveness of the test.

\section{Abbreviations}

BMI: Body-mass index; CES-D: Center for epidemiologic studies depression scale; FFMI: Free fat mass index; IPAQ: International physical activity questionnaire; PSQI: Pittsburgh sleep quality index

\section{Acknowledgments}

The authors thank the patients and personnel at the hospital for their cooperation during the course of this study.

\section{Authors' contributions}

$\mathrm{MH}, \mathrm{KL}$ and $\mathrm{SH}$ conceived and designed the study and drafted the manuscript. $\mathrm{MH}$ and $\mathrm{SH}$ analyzed the data. $\mathrm{MH}, \mathrm{KL}, \mathrm{TL}, \mathrm{WL}$, and $\mathrm{SH}$ substantively contributed to drafting the manuscript. $\mathrm{MH}$ and $\mathrm{SH}$ reviewed the manuscript. All authors have read and approved the manuscript.

\section{Funding}

This study was supported by grants from the Ministry of Science and Technology (MOST 99-2410-H-418-001-MY3 and MOST 108-2314-B-038-113MY3) and Taipei Medical University (106TMU-SHH-17 and 107TMU-SHH-04) The authors and their contributions to the manuscript are independent of the funder. The funder had no role in the design of the study and collection, analysis, and interpretation of the data and in writing the manuscript.

\section{Availability of data and materials}

The datasets are not publicly available due to ethical reasons, but are available from the corresponding author on reasonable request.

\section{Ethics approval and consent to participate}

The study was approved by the Ethics Committee of the Far Eastern Memorial Hospital (no. 098101-3), and all patients provided informed written consent before they were allowed to participate in the study.

\section{Consent for publication}

Not applicable.

\section{Competing interests}

The authors declare no competing interests.

\section{Author details}

'Department of Nursing, Yuanpei University of Medical Technology, Hsinchu City, Taiwan. ${ }^{2}$ Division of Pulmonary Medicine, Department of Internal Medicine, Shuang Ho Hospital, Taipei Medical University, New Taipei City, Taiwan. ${ }^{3}$ Division of Pulmonary Medicine, Department of Internal Medicine, School of Medicine, College of Medicine, Taipei Medical University, Taipei
City, Taiwan. ${ }^{4}$ Department of Physical Medicine and Rehabilitation, Far Eastern Memorial Hospital, New Taipei City, Taiwan. ${ }^{5}$ Shih-Chien Rehabilitation Clinic, Medical Deputy Superintendent, Taipei City, Taiwan. ${ }^{6}$ Division of Geriatric Medicine, Department of Family Medicine, Taipei Medical University, 250 Wuxing Street, Taipei City, Taiwan. ${ }^{7}$ School of Respiratory Therapy, College of Medicine, Taipei Medical University, Taipei City, Taiwan. ${ }^{8}$ School of Respiratory Therapy, College of Medicine, Taipei Medical University, 250 Wuxing Street, Taipei City 11031, Taiwan.

Received: 10 February 2020 Accepted: 10 January 2021

Published online: 19 January 2021

\section{References}

1. Buysse DJ, Reynolds CF 3rd, Monk TH, Berman SR, Kupfer DJ. The Pittsburgh sleep quality index: a new instrument for psychiatric practice and research. Psychiatry Res. 1989;28(2):193-213 Epub 1989/05/01.

2. Landry GJ, Best JR, Liu-Ambrose T. Measuring sleep quality in older adults: a comparison using subjective and objective methods. Front Aging Neurosci. 2015;7:166 Epub 2015/10/07.

3. Kushida CA, Littner MR, Morgenthaler T, Alessi CA, Bailey D, Coleman J Jr, et al. Practice parameters for the indications for polysomnography and related procedures: an update for 2005. Sleep. 2005;28(4):499-521 Epub 2005/09/21

4. Moul DE, Nofzinger EA, Pilkonis PA, Houck PR, Miewald JM, Buysse DJ. Symptom reports in severe chronic insomnia. Sleep. 2002;25(5):553-63 Epub 2002/08/02.

5. Takamatsu S, Sekine M, Tatsuse T, Kagamimori S. Alcohol drinking patterns and sleep quality of Japanese civil servants. Sangyo eiseigaku zasshi. 2010; 52(1):1-11 Epub 2009/11/28

6. Wu CY, Su TP, Fang CL, Yeh CM. Sleep quality among community-dwelling elderly people and its demographic, mental, and physical correlates. J Chin Med Assoc. 2012;75(2):75-80 Epub 2012/02/22.

7. Sariyildiz MA, Batmaz I, Bozkurt M, Bez Y, Cetincakmak MG, Yazmalar L, et al. Sleep quality in rheumatoid arthritis: relationship between the disease severity, depression, functional status and the quality of life. J Clin Med Res. 2014;6(1):44-52 Epub 2014/01/09.

8. Sherrill DL, Kotchou K, Quan SF. Association of physical activity and human sleep disorders. Arch Intern Med. 1998;158(17):1894-8 Epub 1998/10/06.

9. Park YH. Physical activity and sleep patterns in elderly who visited a community senior center. Taehan Kanho Hakhoe chi. 2007;37(1):5-13 Epub 2007/03/07.

10. Zavecz Z, Nagy T, Galko A, Nemeth D, Janacsek K. The relationship between subjective sleep quality and cognitive performance in healthy young adults: evidence from three empirical studies. Sci Rep. 2020;10(1):4855 Epub 2020/ $03 / 19$.

11. Haseli-Mashhadi N, Dadd T, Pan A, Yu Z, Lin X, Franco OH. Sleep quality in middle-aged and elderly Chinese: distribution, associated factors and associations with cardio-metabolic risk factors. BMC Public Health. 2009;9: 130 Epub 2009/05/12.

12. Hoffman S. Sleep in the older adult: implications for nurses (CE). Geriatr Nurs. 2003;24(4):210-4 quiz 5-6. Epub 2003/10/16.

13. Spencer RM, Gouw AM, Ivry RB. Age-related decline of sleep-dependent consolidation. Learn Mem. 2007;14(7):480-4 Epub 2007/07/12.

14. Yang CY, Chiou AF. Predictors of sleep quality in community-dwelling older adults in northern Taiwan. J Nurs Res. 2012;20(4):249-60 Epub 2012/11/17.

15. Moreno-Vecino B, Arija-Blazquez A, Pedrero-Chamizo R, Gomez-Cabello A, Alegre LM, Perez-Lopez FR, et al. Sleep disturbance, obesity, physical fitness and quality of life in older women: EXERNET study group. Climacteric. 2017; 20(1):72-9 Epub 2017/01/04

16. Lee AJ, Lin WH. Association between sleep quality and physical fitness in female young adults. J Sports Med Phys Fitness. 2007;47(4):462-7 Epub 2007/12/20.

17. Kline CE. The bidirectional relationship between exercise and sleep: implications for exercise adherence and sleep improvement. Am J Lifestyle Med. 2014;8(6):375-9 Epub 2015/03/03.

18. Tsai PS, Wang SY, Wang MY, Su CT, Yang TT, Huang CJ, et al. Psychometric evaluation of the Chinese version of the Pittsburgh sleep quality index (CPSQI) in primary insomnia and control subjects. Qual Life Res. 2005;14(8): 1943-52 Epub 2005/09/13.

19. Liou YM, Jwo CJ, Yao KG, Chiang LC, Huang LH. Selection of appropriate Chinese terms to represent intensity and types of physical 
activity terms for use in the Taiwan version of IPAQ. J Nurs Res. 2008; 16(4):252-63 Epub 2008/12/09.

20. Lin PS, Hsieh CC, Cheng HS, Tseng TJ, Su SC. Association between physical fitness and successful aging in Taiwanese older adults. PLoS One. 2016; 11(3):e0150389 Epub 2016/03/11.

21. Andresen EM, Malmgren JA, Carter WB, Patrick DL. Screening for depression in well older adults: evaluation of a short form of the CES-D (Center for Epidemiologic Studies Depression Scale). Am J Prev Med. 1994;10(2):77-84 Epub 1994/03/01.

22. Gerber M, Brand S, Holsboer-Trachsler E, Puhse U. Fitness and exercise as correlates of sleep complaints: is it all in our minds? Med Sci Sports Exerc. 2010;42(5):893-901 Epub 2009/12/10.

23. Taylor-Gjevre RM, Gjevre JA, Nair B, Skomro R, Lim HJ. Components of sleep quality and sleep fragmentation in rheumatoid arthritis and osteoarthritis. Musculoskelet Care. 2011;9(3):152-9 Epub 2011/06/08.

24. Goes $A C J$, Reis $L A B$, Silva MBG, Kahlow BS, Skare TL. Rheumatoid arthritis and sleep quality. Rev Bras Reumatol. 2017;57(4):294-8 Epub 2017/08/16.

25. Chen HC, Hsu NW, Chou P. The association between sleep duration and hand grip strength in community-dwelling older adults: the yilan study, Taiwan. Sleep. 2017;40(4):1-8. Epub 017/02/16.

26. Tsuno N, Besset A, Ritchie K. Sleep and depression. J Clin Psychiatry. 2005; 66(10):1254-69 Epub 2005/11/02.

27. Barclay NL, Eley TC, Buysse DJ, Rijsdijk FV, Gregory AM. Genetic and environmental influences on different components of the Pittsburgh sleep quality index and their overlap. Sleep. 2010;33(5):659-68 Epub 2010/05/18.

\section{Publisher's Note}

Springer Nature remains neutral with regard to jurisdictional claims in published maps and institutional affiliations.

Ready to submit your research? Choose BMC and benefit from:

- fast, convenient online submission

- thorough peer review by experienced researchers in your field

- rapid publication on acceptance

- support for research data, including large and complex data types

- gold Open Access which fosters wider collaboration and increased citations

- maximum visibility for your research: over $100 \mathrm{M}$ website views per year

At $\mathrm{BMC}$, research is always in progress.

Learn more biomedcentral.com/submissions 